\title{
The Effect of Colemanite on Thermal Properties of Recycled Polyethylene
}

\author{
İ. BILICI* \\ Department of Chemical Engineering, Hitit University, 19030, Corum, Turkey
}

\begin{abstract}
Boron is known as a rare and one of the most important elements for future engineering. Boron is naturally present in nature in the form of minerals, such as tincal, ulexite, colemanite, boracite, datolite and so on. Besides of the healthy benefits, it has numerous application area from agricultural applications to space technology. The boron derived chemicals, such as borones, borates, borohydrides, boronic acids and other boron compounds, are applied from nano- to macroscale. In this study, usage of boron mineral was investigated as a raw material in colemanite form without any chemical treatment. For this purpose polyethylene-colemanite composites were produced and characterized thermally. Polyethylene was used as a binder and colemanite as a matrix material. Used materials were characterized before process via the Fourier transform infrared spectroscopy and differential scanning calorimetry. Thermomechanical analysis and limiting oxygen index tests were also performed in order to determine the thermal and inflammability properties of the composite. The results show that colemanite play an ultimate role in composites for flammable properties and mechanical performance. These properties can be controlled by proper adjustments of the amount of colemanite in the composite.
\end{abstract}

DOI: 10.12693/APhysPolA.135.922

PACS/topics: colemanite, recycled polyethylene, composite, DSC, TMA, LOI

\section{Introduction}

Elemental boron is obtained by processing minerals such as ulexite, tinkal and colemanite. This requires a specific processes, which brings extra cost [1]. In the recent years, different applications of colemanite were considered, e.g. as a hydrogen storage material [2], cement and bitumen additives [3], or neutron shield material. It is stated that the evaluation of these materials, in which domestic and industrial wastes are used, is very important in terms of waste management [4]. Waste materials such as date shell [5], fly ash [6], peach nut shell [7] are considered as useless and every possibility of its reclaim can be precious. Binders may be thermoset and thermoplastic materials such as urea formaldehyde [8], polypropylene [9].

In this study, the polyethylene obtained from recycled plastics was used as binder and the thermal effects of using colemanite as boron-based additive material in prepared composites were investigated. Polyethylene characterized by the Fourier transform infrared spectrography (FTIR) and differential scanning calorimetry (DSC). The manufactured composite materials were characterized by DSC and thermomechanical analysis (TMA) for the investigation of heat behavior and change of the softening temperature of the material depending on the temperature. Finally, limit oxygen index (LOI) of many manufactured composites was measured to determine flame retardancy properties.

*e-mail: ibrahimbilici@hitit.edu.tr

\section{Experimental procedure}

Colemanite obtained from Eti Mining General Directorate and recycled polyethylene from Guangzhou Lushan New Materials Co. were mixed at $170{ }^{\circ} \mathrm{C}$ for 20 minutes at $50 \mathrm{rpm}$. Recycled polyethylene characterized by FTIR and DSC. Obtained polymer-colemanite mixture crushed via shredder and injected to proper shape at 800 bar initial pressure and 200 bar final pressure during 5 second and 20 second respectively was submitted to three point bending test. DSC analysis carried out between $25^{\circ} \mathrm{C}-250^{\circ} \mathrm{C}$ under $20 \mathrm{~mL} / \mathrm{min}$ air flow rate at $10^{\circ} \mathrm{C} / \mathrm{min}$ temperature growth rate. TMA analysis carried out $115^{\circ} \mathrm{C}$ isothermal condition under $0.1 \mathrm{~N}$ constant load via three point bending apparatus. LOI values for obtained composites were determined according to ASTM D2863.

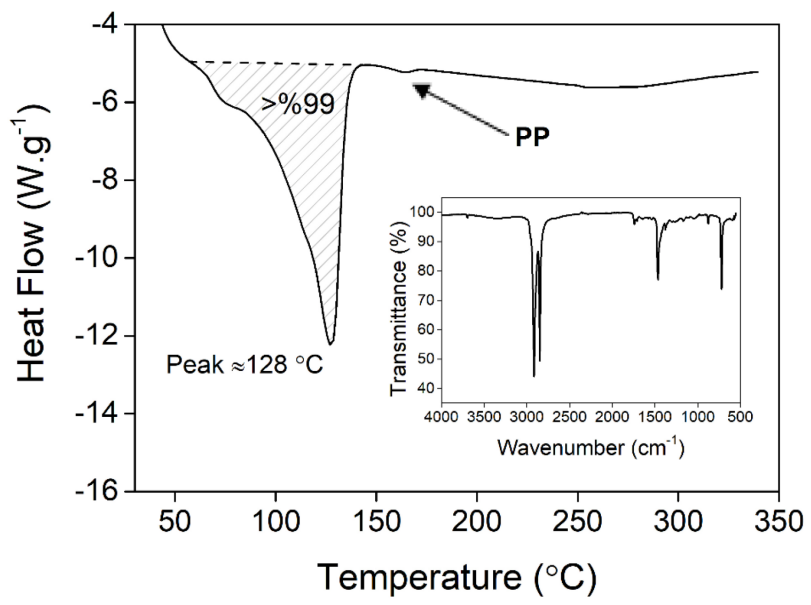

Fig. 1. FTIR spectroscopy analysis in DSC results of polyethylene. 


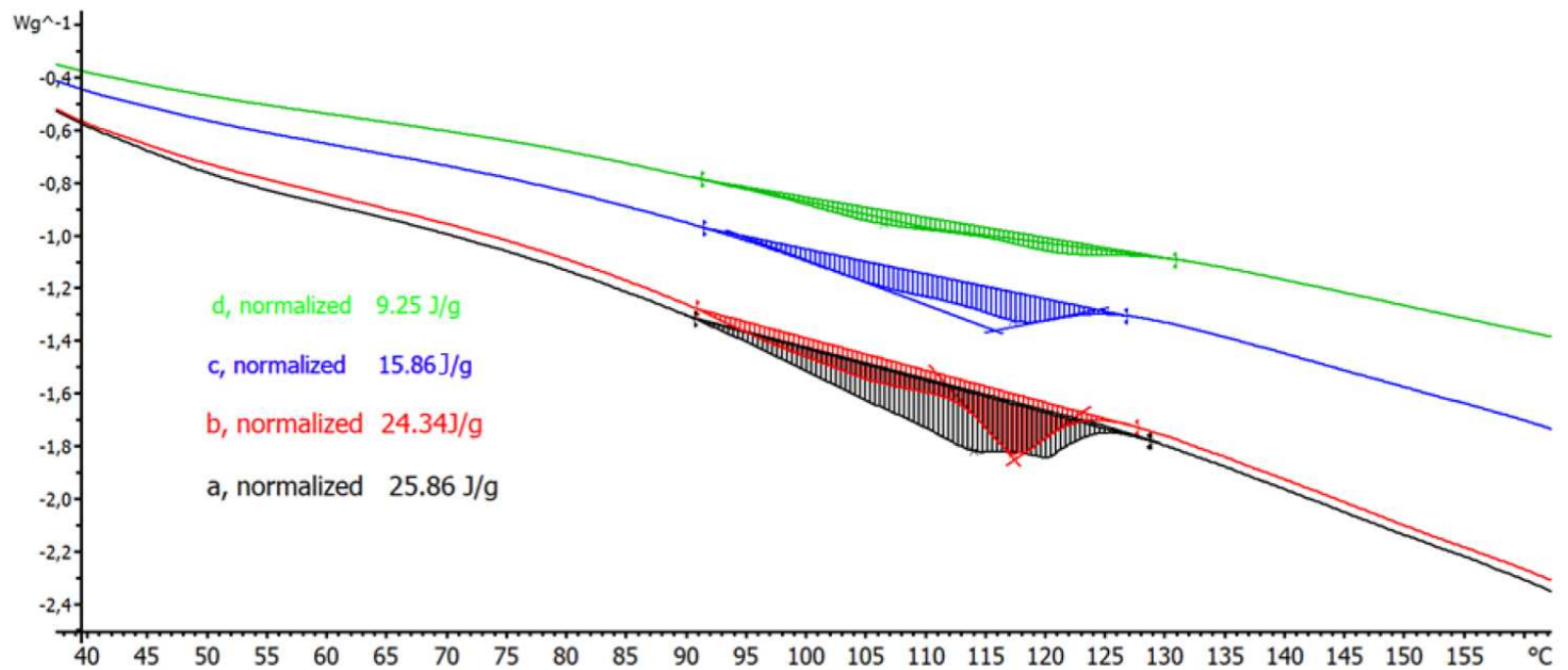

Fig. 2. DSC results of composites based on colemanite percentage (a) 50\%, (b) 60\%, (c) 70\%, (d) $80 \%$.
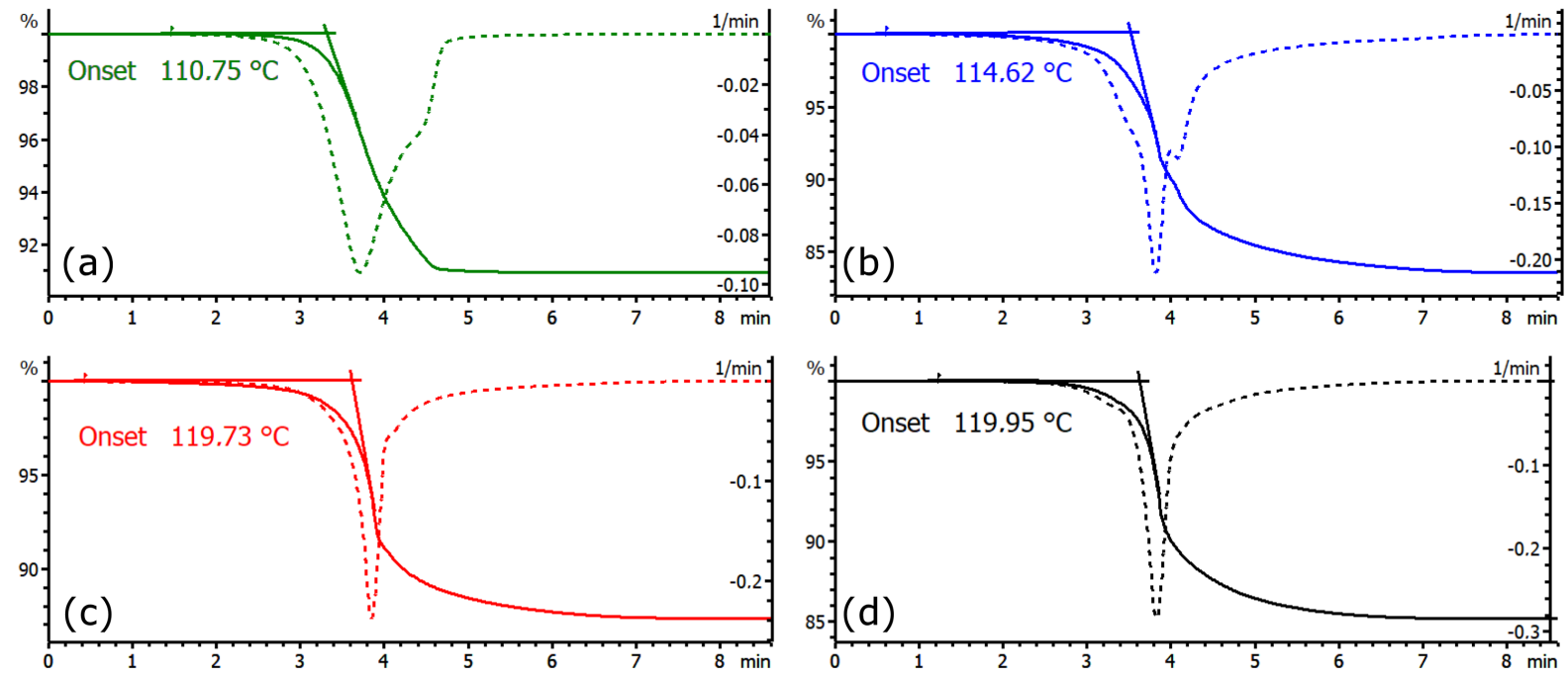

Fig. 3. TMA results of composites based on colemanite percentage (a) 50\%, (b) $60 \%$, (c) $70 \%$, (d) $80 \%$.

\section{Results and discussion}

FTIR spectrum in Fig. 1 confirms that bonding material is polyethylene. The additional DSC analysis is subsidiary to FTIR spectrum measurement. It supports the previous results and also gives a negligible peak at $164^{\circ} \mathrm{C}$ which belong to polypropylene [10]. The utilized polyethylene utilized in the experiment is a recycled material, and therefore the visible deformation of spectra due to various impurities should not be the surprise.

As shown in Fig. 2 determined normalized peak values in DSC indicate that endothermic melting peaks were reduced depending on the amount of polyethylene [11].

Figure 3 shows that the softening point at $110^{\circ} \mathrm{C}$ under $0.1 \mathrm{~N}$ constant force. Increasing amount of colemanite effected to softening temperature raised from about $110^{\circ} \mathrm{C}$ to $120^{\circ} \mathrm{C}$ assertively. It means that colemanite influence to material durability is positive and working temperature of polyethylene is increased either.
In Fig. 4, dependence of LOI values on the colemanite contents reveals is influence as a flame retardant. As expected, LOI values are increased with the increasing amount of colemanite from $23 \%$ to $31 \%$ [11].

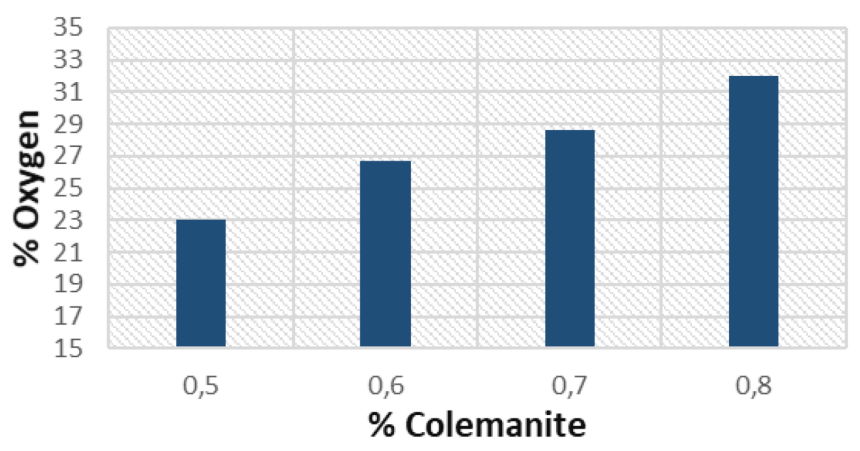

Fig. 4. LOI results of composites based on colemanite percentage. 


\section{Conclusion}

As a result, colemanite has been successfully mixed with recycled polyethylene up to $80 \%(\mathrm{w} / \mathrm{w})$. It is very good result for polyethylene and colemanite ratio. These substances were not expected to blend with each other due to their quasi-miscibility. By adding compatibilizer into the mixture, and examining the mixing characteristics, more suitable production methods can be proposed to obtain the desired properties. The resultant material is suitable for layered composites in terms of fire resistance and thermal durability. The increase in the mechanical strength with the temperature can be further increased by the extra additives. If some other commercial additives such as antioxidant additives or UV additives are investigated, the areas where it can be used commercially can also be expanded. Furthermore, gamma shielding property and oxidation induction time of the composite materials obtained in this study can also be investigated for even better results.

\section{References}

[1] Boron in Turkey, Eti Maden, Ankara 2018.

[2] A.F. Karabulut, M. Guru, T.A. Boynueğri, M.Y. Aydin, J. Electron. Mater. 45, 3957 (2016).
[3] A. Öcal, M. Gürü, M. Karacasu, J. Fac. Eng. Arch. Gazi Univ. 33, 939 (2018).

[4] A. Nandan, B.P. Yadav, S. Baksi, D. Bose, World Sci. News 66, 56 (2017).

[5] H.M. Taşdemir, A. ŞAHİN, A.F. Karabulut, M. Gürü, J. Fac. Eng. Arch. Gazi Univ. 18, (2018).

[6] M. Gürü, M. Şahin, S. Tekeli, H. Tokgöz, High Temp. Mater. Proc. 28, 191 (2009).

[7] A. Sahin, H.M. Tasdemir, A.F. Karabulut, M. Gürü, Arab. J. Sci. Eng. 42, 1559, (2017).

[8] M. Gürü, S. Tekeli, İ. Bilici, Mater. Des. 27 1148, (2006).

[9] A.H. Youssef, C. Mouli, R. Madhuranthakam, A. Elkamel, V. Mittal, J. Thermoplast. Compos. Mater. 28849 (2015).

[10] A.C.-Y. Wong, F. Lam, Polymer Testing 21691 (2002).

[11] E. Terzi, Biores. 13 4239, (2018). 